\title{
CXLII. THE NATURE OF PAPAIN
}

\author{
By C. V. GANAPATHY AND B. N. SASTRI \\ From the Department of Biochemistry, Indian Institute of \\ Science, Bangalore
}

(Received 25 May 1939)

THE widely accepted view that active papain contains SH groups, its oxidation to the disulphide form leading to its inactivation [Bersin, 1933; Purr, 1935] appears to be untenable in the light of more recent work. The irreversible inactivation of papain by iodoacetic acid, even in low concentrations, cannot be satisfactorily explained on the basis of its thiol nature, whilst the inhibition of its action on hippurylamide or on carbobenzyloxyisoglutamine by phenylhydrazine and acceleration of the action on albumin peptone by the same reagent, observed by Bergmann \& Ross [1936] cannot be interpreted on simple oxidation-reduction considerations. In fact, Okumura [1938] working with purified papain preparations regards papain as a "special" protein containing an aldehyde group but neither a SH or SS group.

Bergmann's researches on papain [cf. Bergmann \& Ross, 1936], employing synthetic substrates, led him to the view that its behaviour can best be explained on the basis that papain is a two-enzyme system, a view which he subsequently considered superfluous. Frankel et al. [1937], however, employing the fresh latex of Carica papaya as a source of the enzyme, adduced evidence to show that gelatin cleavage and peptone cleavage were two distinct processes. It thus appears that both the thiol nature of papain and its homogeneity have been questioned.

For reasons already mentioned in our earlier paper [Ganapathy \& Sastri, $1938,1]$, it is imperative for any work on the nature of papain to employ preparations obtained from freshly tapped latex of $C$. papaya. The results reported in this paper, obtained with such preparations, throw some light on the complexity of the enzyme. A preliminary communication on the subject appeared in Nature [Ganapathy \& Sastri, 1938, 2].

\section{EXPERIMENTAL}

The papain preparations employed in this study were all obtained from the fresh latex of $C$. papaya grown in the Institute nursery.

$S H$-papain. Fresh latex (100 g.) was stirred up vigorously with 5 times its weight of water and filtered. The enzyme was precipitated from the filtrate by the addition of 5 vol. absolute alcohol. The precipitate was centrifuged, dissolved in water, filtered and the enzyme precipitated by the addition of alcohol, the process being repeated 3 times. The final precipitate was washed on the centrifuge with absolute alcohol and dried over $\mathrm{CaCl}_{2}$ in a vacuum desiccator. The extractions and precipitations were carried out in the cold room at $0^{\circ}$ (yield $11 \%$ ).

SS-papain. Fresh latex (100 g.) was stirred up with 5 times its weight of water and $2 \mathrm{ml}$. of $\mathrm{H}_{2} \mathrm{O}_{2}$ (Merck's $30 \%$ ) for about $1 \mathrm{hr}$. The supernatant fluid, at this stage, failed to give any test with nitroprusside. The precipitate obtained 
by adding 5 vol. absolute alcohol to the clear filtrate, was separated by centrifuging, dissolved in water, treated again with $2 \mathrm{ml} . \mathrm{H}_{2} \mathrm{O}_{2}$, filtered and the enzyme precipitated by the addition of alcohol, the process being repeated 3 times. The final precipitate was washed on the centrifuge with absolute alcohol and dried over $\mathrm{CaCl}_{2}$ in vacuo (yield $12 \%$ ).

SS-papain preparations were also obtained by employing alloxan as the oxidizing agent. The procedure was essentially similar, except that the latex extract and alloxan were kept at room temperature $\left(25-27^{\circ}\right)$ for $12 \mathrm{hr}$. before precipitating the enzyme by alcohol. The red colour developed during this treatment could be eliminated by means of decolorizing carbon.

Four different preparations were obtained from samples of latex tapped on different days. The substrates employed were gelatin (gold label), egg albumin, Witte's peptone, Roche peptone, silk peptone and hippurylamide. The HCN activations were carried out according to the method of Willstätter \& Grassmann [1924].

The reaction mixture consisted of $5 \mathrm{ml}$. of $5 \%$ enzyme solution, $5 \mathrm{ml}$. of substrate ( 5 or $10 \%$ ), $5 \mathrm{ml}$. of McIlvaine's citrate-phosphate buffer (twice the

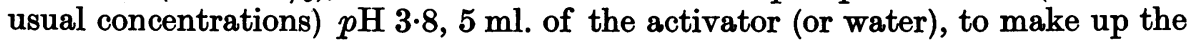
total volume to $20 \mathrm{ml}$. The activity was determined by pipetting out $2 \mathrm{ml}$. of the reaction mixture after $24 \mathrm{hr}$. incubation at $38^{\circ}$ into $2 \mathrm{ml}$. of $40 \%$ formaldehyde and titrating against $0 \cdot 1 \mathrm{~N}$ alkali with phenolphthalein as indicator. The figures in the following tables indicate increase in formaldehyde titration (ml. of $0 \cdot 1 \mathrm{~N}$ alkali).

Table I. SH-papain

Substrate (10\%)
Gelatin without HCN
Gelatin with HCN
Peptone without HCN
Peptone with HCN

\begin{tabular}{cccc}
\multicolumn{4}{c}{ ml. of $0.1 \mathrm{~N} \mathrm{NaOH}$} \\
Prep. I & Prep. II & Prep. III & Prep. IV \\
0.76 & 0.67 & 1.04 & 0.70 \\
1.35 & 1.35 & 1.08 & 1.19 \\
1.12 & 1.10 & 1.18 & 1.27 \\
1.16 & 1.17 & 1.34 & 1.35
\end{tabular}

Table II. SS-papain

\begin{tabular}{|c|c|c|c|c|c|c|}
\hline \multirow[b]{2}{*}{ Substrate (5\%) } & \multicolumn{6}{|c|}{ ml. of $0.1 \mathrm{~N} \mathrm{NaOH}$} \\
\hline & $\begin{array}{c}\text { Prep. } \\
\text { I }\end{array}$ & $\begin{array}{c}\text { Prep. } \\
\text { II }\end{array}$ & $\begin{array}{c}\text { Prep. } \\
\text { III }\end{array}$ & $\begin{array}{c}\text { Prep. } \\
\text { IV }\end{array}$ & $\underset{V^{*}}{\text { Prep. }}$ & $\underset{\text { VI }}{\text { Prep. }}$ \\
\hline Gelatin without HCN & $0 \cdot 25$ & 0.18 & $0 \cdot 36$ & 0.34 & $0 \cdot 60$ & 0.52 \\
\hline Gelatin with HCN & 0.48 & 0.30 & $0 \cdot 81$ & 0.80 & - & - \\
\hline Peptone without HCN & 0.00 & 0.00 & 0.01 & 0.01 & 0.08 & 0.05 \\
\hline Peptone with HCN & $0 \cdot 40$ & $\mathbf{0} \cdot \mathbf{3 1}$ & 0.50 & $0 \cdot 48$ & - & 一 \\
\hline
\end{tabular}

Table III. SS-papain with different buffers

Substrate
$5 \%$
Gelatin
Peptone

\begin{tabular}{|c|}
\hline $\begin{array}{l}\text { Without } \\
\text { buffer }\end{array}$ \\
\hline $\begin{array}{l}0 \cdot 19 \\
0.00\end{array}$ \\
\hline
\end{tabular}
Acetic acid- acetate
$0 \cdot 25$
$0 \cdot 01$

Phosphate-
citrate
0.27
0.02

It will be seen from Table II that the SS-preparation, strikingly enough, hydrolyses gelatin but not peptone unless activated by HCN. It may be mentioned here that the reaction mixtures, except when treated with cyanide, failed to give the test with nitroprusside both before and after the reaction. Activation can be effected by $\mathrm{H}_{2} \mathrm{~S}$, cysteine or glutathione. Identical results were obtained 
with both citrate and acetate buffers, showing that the results are not influenced by the presence of buffer salts (Table III).

The results obtained with different substrates are given in Table IV.

Table IV. Action on various substrates

\begin{tabular}{|c|c|c|c|c|}
\hline \multirow[b]{2}{*}{ Substrate* } & \multicolumn{2}{|c|}{ SS-papain } & \multicolumn{2}{|c|}{ SH-papain } \\
\hline & $\begin{array}{c}\text { Without } \\
\text { HCN }\end{array}$ & $\begin{array}{l}\text { With } \\
\text { HCN }\end{array}$ & $\begin{array}{c}\text { Without } \\
\text { HCN }\end{array}$ & $\begin{array}{l}\text { With } \\
\text { HCN }\end{array}$ \\
\hline Gelatin & $0 \cdot 36$ & $0 \cdot 85$ & $0 \cdot 76$ & 1.01 \\
\hline Egg albumin & $0 \cdot 24$ & $0 \cdot 25$ & $0 \cdot 26$ & $0 \cdot 28$ \\
\hline Witte's peptone & 0.01 & 0.48 & $1 \cdot 16$ & $1 \cdot 18$ \\
\hline Silk peptone & 0.02 & $0 \cdot 44$ & $0 \cdot 66$ & $0 \cdot 70$ \\
\hline Roche peptone & 0.01 & $0 \cdot 46$ & 0.44 & $0 \cdot 46$ \\
\hline Hippurylamide & 0.00 & 0.40 & $0 \cdot 46$ & 0.56 \\
\hline
\end{tabular}

* For SS-papain the substrate concentration was $5 \%$ while for SH-papain it was $10 \%$.

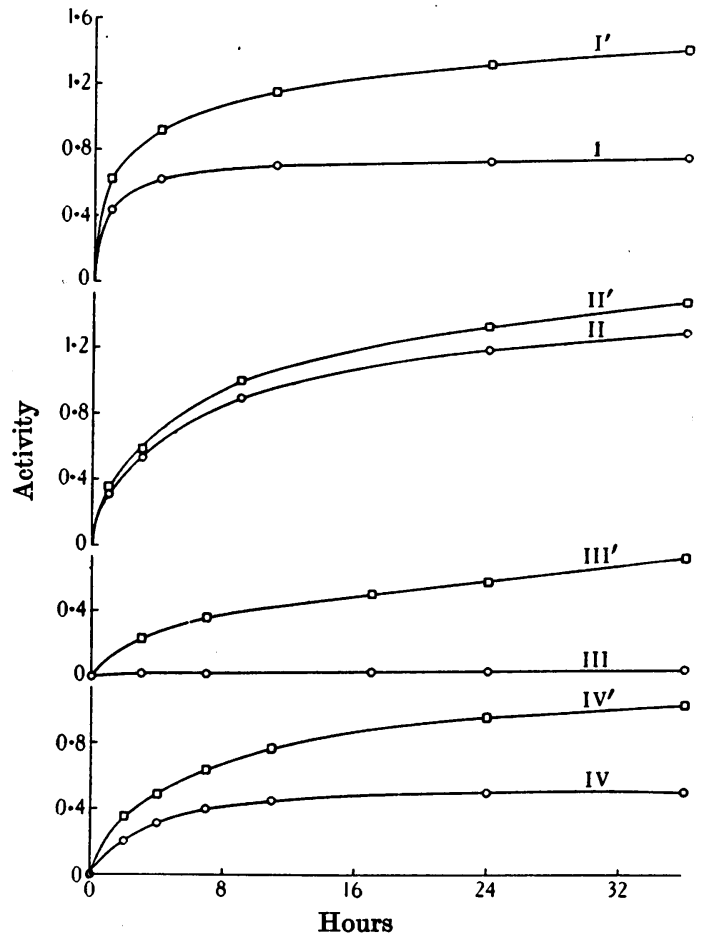

Fig. 1.
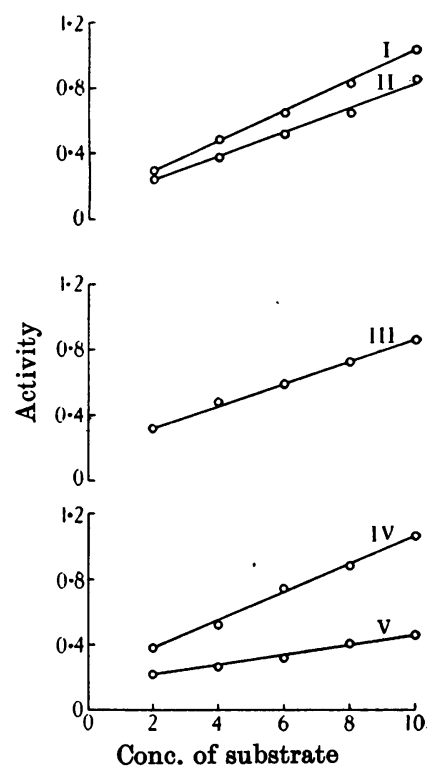

Fig. 2.

Fig. 1. Hydrolysis of gelatin and peptone by SH- and SS-papain. I, SH-papain plus gelatin; II, SH-papain plus peptone; III, SS-papain plus peptone; IV, SS-papain plus gelatin; $\mathrm{I}^{\prime}, \mathrm{II}^{\prime}, \mathrm{III}^{\prime}, \mathrm{IV}^{\prime}$, corresponding activities in the presence of cyanide.

Fig. 2. Influence of substrate concentration on the rate of hydrolysis of gelatin and peptone by SH- and SS-papain. I, Natural papain plus gelatin; II, natural papain plus peptone; III, SSpapain plus cyanide plus peptone; IV, SS-papain plus cyanide plus gelatin; V, SS-papain plus gelatin.

SS-papain hydrolyses both egg albumin as well as gelatin but has no action on peptones or hippurylamide. 
The courses of hydrolysis of gelatin and peptone by SH- and SS-papain preparations are indicated in Fig. 1. Natural papain, i.e. a filtered aqueous extract of the fresh latex, which contains a large concentration of sulphydryl compounds behaves exactly like the precipitated SH-preparation, in that there is only a slight increase in the degree of hydrolysis in the presence of cyanide.

Fig. 2 shows the variations in the hydrolysis of gelatin and peptone by SHand SS-papains, with increase in the substrate concentration. The relationship is more or less linear.

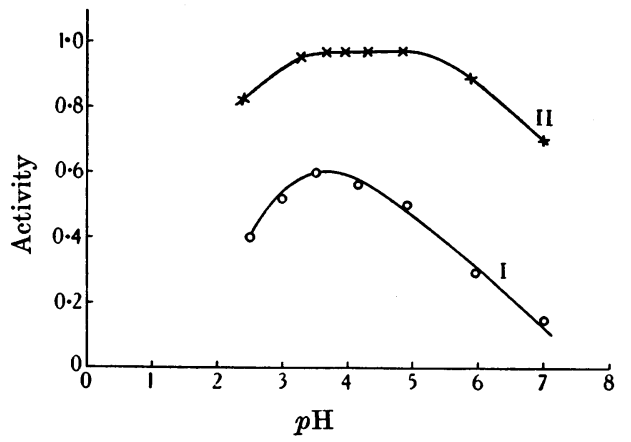

Fig. 3. Influence of $p \mathrm{H}$ on the hydrolysis of gelatin by SH- and SS-papain; I, SS-papain; II, SH-papain.

Fig. 3 shows the influence of $p \mathrm{H}$ on the hydrolysis of gelatin by SH- and SS-papain preparations. The optimum activity in the case of SH-papain is spread over the range $p \mathrm{H}$ 3-5. The SS-preparation, has a sharp optimum at $p \mathrm{H} \mathrm{3 \cdot 6-3 \cdot 8}$.

The influence of added substances. Table $\mathrm{V}$ shows the influence of adding maleic acid, glutathione, iodoacetic acid and HCN on the hydrolyses of gelatin and peptone by SH- and SS-papain preparations.

\begin{tabular}{|c|c|c|c|c|}
\hline \multicolumn{5}{|c|}{ Table V } \\
\hline & \multicolumn{2}{|c|}{ SH-papain } & \multicolumn{2}{|c|}{ SS-papain } \\
\hline Activator & Gelatin & Peptone & Gelatin & Peptone \\
\hline Unactivated & 0.47 & 0.56 & $0 \cdot 27$ & $0 \cdot 00$ \\
\hline $\mathrm{HCN}(1 \%)$ & 0.68 & 0.58 & 0.46 & $0 \cdot 40$ \\
\hline Glutathione $20 \mathrm{mg}$. & $0 \cdot 70$ & $0 \cdot 61$ & 0.50 & $0 \cdot 44$ \\
\hline Maleic acid $15 \mathrm{mg}$. & $0 \cdot 31$ & 0.08 & $0 \cdot 27$ & 0.00 \\
\hline Iodoacetic acid $0.1 \mathrm{mg}$. & 0.00 & 0.00 & 0.00 & $0 \cdot 00$ \\
\hline
\end{tabular}

\section{Discussion}

The oxidized preparations which give negative nitroprusside tests, possess considerable activity towards gelatin while being without effect on peptone. This observation warrants the conclusion that for "gelatinase" activity of papain the SH group is not essential. The "gelatinase" activity of the SS-papain preparation corresponds to about $60 \%$ of the "full" (i.e. HCN-activated) activity.

It has been shown by Hopkins et al. [1938] that those enzymes which depend for their activity on the presence of a SH group are specifically inactivated by maleic acid. The figures given in Table V show that while "gelatinase" activity is not affected by the addition of maleic acid, the "peptonase" activity of the SH-preparation is inhibited. This further supports the view that 
the SH group is not essential for "gelatinase" action; it appears to be necessary for "peptonase" action.

Iodoacetic acid inactivates both SH- and SS-preparations; the inactivation is irreversible and the amount required for this inactivation is far less than is necessary for reacting with the SH groups. This shows that both for gelatinase and peptonase activities some group (or groups) other than $\mathrm{SH}$ is essential.

\section{SUMMARY}

1. Preparations of papain (SS-papain) obtained by completely oxidizing the $\mathrm{SH}$ groups of natural papain by $\mathrm{H}_{2} \mathrm{O}_{2}$ or alloxan, retain the property of hydrolysing gelatin or egg albumin. They are however inactive towards peptones.

2. The optimum $p \mathrm{H}$ for gelatin hydrolysis by SS-papain is $3 \cdot 6-3 \cdot 8$; that for hydrolysis by SH-papain is spread over the range $p \mathrm{H} 3-5$.

3. Cyanide and glutathione activate SS-papain; this activation extends the range of action of the enzyme, which is then capable of hydrolysing peptones. Maleic acid is without effect on gelatinase; it inhibits the hydrolysis of peptone by SH-papain. Iodoacetic acid inactivates irreversibly both SH- and SS-papain preparations.

4. The SH group is not essential for gelatinase activity; it appears, however, to be necessary for peptonase activity. Another group which reacts with iodoacetic acid irreversibly appears to be essential for both the gelatinase and peptonase activities.

\section{REFERENCES}

Bergmann \& Ross (1936). J. biol. Chem. 114, 717.

Bersin (1933). Hoppe-Seyl. Z. 222, 177.

Frankel, Mannin \& Shapiro (1937). Biochem. J. 31, 1926.

Ganapathy \& Sastri (1938, 1). Proc. Ind. Acad. Sci. 7, 399. (1938, 2). Nature, Lond., 142, 539.

Hopkins \& Morgan (1938). Biochem. J. 32, 611 .

- \& Lutwak-Mann (1938). Biochem. J. 32, 1829.

Okumura (1938). Bull. Chem. Soc. Japan, 13, 534.

Purr (1935). Biochem. J. 29, 5.

Willstätter \& Grassmann (1924). Hoppe-Seyl. Z. 138, 184. 